\title{
HispanismeS
}

Revue de la Société des Hispanistes Français

$17 \mid 2021$

Murs, barrières, obstacles dans les mondes

hispaniques I

\section{La condición sudamericana en la prensa de fines de siglo XIX}

Pequeñas confrontaciones culturales

La condition sud-américaine dans la presse de la fin du XIXe siècle. Petites

confrontations culturelles

The South American condition in the press of the late nineteenth century. Small

cultural confrontations

\section{Silvana Gardie}

\section{CpenEdition}

Journals

Edición electrónica

URL: https://journals.openedition.org/hispanismes/13365

DOI: 10.4000/hispanismes.13365

ISSN: 2270-0765

Editor

Société des Hispanistes Français

Referencia electrónica

Silvana Gardie, «La condición sudamericana en la prensa de fines de siglo XIX», HispanismeS [En línea] 17 | 2021, Publicado el 01 junio 2021, consultado el 27 enero 2022. URL: http://

journals.openedition.org/hispanismes/13365; DOI: https://doi.org/10.4000/hispanismes. 13365

Este documento fue generado automáticamente el 27 enero 2022

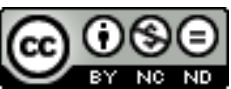

Les contenus de cette revue sont mis à disposition selon les termes de la Licence Creative Commons Attribution - Pas d'Utilisation Commerciale - Pas de Modification 4.0 International. 


\title{
La condición sudamericana en la prensa de fines de siglo XIX
}

\author{
Pequeñas confrontaciones culturales \\ La condition sud-américaine dans la presse de la fin du XIXe siècle. Petites \\ confrontations culturelles \\ The South American condition in the press of the late nineteenth century. Small \\ cultural confrontations
}

Silvana Gardie

1 Para fines del siglo XIX y dentro del afianzamiento de la modernidad capitalista y su globalización inherente, lo sudamericano siguió encontrándose con los mismos muros, barreras y obstáculos temporales, culturales, físicos y simbólicos que señalaban su desajuste en relación con el tiempo presente de Europa sentido como el pulso real de la civilización occidental. Entiendo por condición sudamericana un dato de identidad resultante del mestizaje y de un origen geopolíticamente periférico en relación con el Viejo Mundo asumido como centro.

2 Sin embargo, las dinámicas democratizadoras presentes en algunas naciones sudamericanas en el último tercio del siglo XIX, como el acceso al viaje europeo y la ampliación de la cultura letrada, generaron un mayor contraste con aquellas barreras prestablecidas. Se trata de procesos que modificaron sustancialmente lo conocido y dieron lugar al «vendaval de lo nuevo» ${ }^{1}$, algo que podríamos asumir como un momento de aceleración de la historia.

3 Por un lado, la democratización del viaje estuvo favorecida por los avances en los medios de transporte y la consolidación de la industria turística, alentada por la publicidad y el elogio de muchos viajeros tradicionales que reconocían el potencial pedagógico que el viaje al Viejo Mundo podía aportar en la formación de los ciudadanos y futuros dirigentes ${ }^{2}$ de la América española. 
4 Por otro lado, la modernización de las comunicaciones, la expansión de la prensa periódica y la conformación de un mercado editorial y de un nuevo público lector promovió la democratización de la cultura letrada.

5 Ambos procesos se expresaron en simultáneo y estuvieron vinculados por una aspiración común: la modernización del Estado nación entendido como mejora social posible a partir de la apertura de ciertos espacios materiales e inmateriales de orden global, así como la superación de las formas tradicionales de distinción dadas por el origen, la sangre o el apellido.

6 En otro trabajo ${ }^{3}$ me detuve en la democratización del viaje a Europa en diversos textos que testimoniaban la incomodidad de los franceses frente a una especie de ola de advenedizos y turistas sudamericanos que inundaba París o bien, el desprecio que los propios viajeros sudamericanos intentaban evadir disimulando los modos autóctonos o idiosincráticos y procurando una asimilación rápida al estilo de vida europeo.

7 En este trabajo me interesa recuperar un acontecimiento vinculado con la democratización de la cultura letrada. Se trata de una serie de publicaciones de la prensa francesa en torno a la representación de la condición sudamericana en la década de 1880 , reproducidas o comentadas a su vez por la prensa local para lectores sudamericanos.

\section{La circulación de la letra impresa: crónica, difamación y réplicas al vacío}

8 La prensa francesa fue una gran máquina discursiva inspiradora de grandes transformaciones dentro de lo que hoy pensamos en torno al diario, las noticias, la función del periodista y corresponsales. Como señala Christian Goubault, en tiempos de Maupassant, al momento en que publica su novela Bel Ami, la prensa estaba en plena expansión, con alrededor de 60 periódicos parisinos en julio de 1880 y sin contar las demás publicaciones periódicas. Dice Goubault:

El progreso industrial, el crecimiento económico de Francia, la ley de 1881 acerca de la libertad de prensa [...] la democracia parlamentaria, la escolarización, el sufragio universal, el descenso de los precios de venta al público, la notoriedad y eclosión de colaboradores, la multiplicidad de títulos cubriendo todo el abanico político, hacen de la prensa el «cuarto poder» y el medio más influyente de comunicación de finales del siglo XIX .

Muchas publicaciones francesas participaron en la construcción de saberes e imaginarios en torno a la condición sudamericana. Por su parte, a partir de la adhesión al servicio telegráfico, la incorporación del reporter y del periodista corresponsal, así como una política editorial siempre interesada por participar en la escena mundial, la prensa sudamericana reprodujo mucho de lo publicado en periódicos parisinos.

10 Precisamente, entre 1886 y 1889 y a propósito de una serie de textos publicados en Le Figaro donde se ridiculizaba la condición sudamericana, algunos escritores sudamericanos buscaron responder a la prensa francesa. Los textos corresponden a escritores que fueron a la vez viajeros avezados, que leían y hablaban perfectamente el francés y eran conscientes de la mirada eurocéntrica de la que nos habla Pratt ${ }^{5}$, una cosmovisión que muchos de estos letrados reprodujeron en sus propios entornos de origen y entre sus compatriotas. 
11 Los textos escritos como réplica a las publicaciones francesas colaboraron en la construcción de una imagen del letrado sudamericano capaz de establecer una confraternidad frente al agravio, tal como sucede en el caso de Martin García Mérou o el caso de Juan Montalvo, quien escribe a pedido de una colectividad que se ha sentido difamada o bien el caso del pronunciamiento de un cosmopolita como Lucio Mansilla quien denunció la estafa intelectual de una publicación francesa plagada de errores sobre la Argentina y que contaba con un prólogo laudatorio de Emile Zola.

\section{Millaud y les exotiques d'Amérique du Sud}

Entre 1885-1886 Albert Millaud, bajo el seudónimo de Labruyère, publicó en Le Figaro una serie de retratos modernos con el título de Physiologies parisiennes ${ }^{6}$, una enorme galería de personajes que aparecen en los bulevares en la Belle Epoque. El diario funcionó como una vidriera por la que era posible verlos en su diversidad y llegar a identificarlos. El diario dio lugar a ese París que devino en centro del espectáculo cosmopolita y escaparate mundial por el que desfilaron los nuevos tiempos con sus modernos tipos sociales. A partir de su apariencia, su fisonomía y su perfil psicológico, fueron retratados «el pequeño telegrafista», «los turfistas de Saint Owen», «el decadente», «el oportunista», «los morfinómanos», y también los americanos tan presentes en París.

En «L'Américain à Paris» ${ }^{7}$ Millaud se ocupa del americano del norte: «un Indien britannisé. Il est rude, actif...et n'admet pas d'obstacles. Il suppose qu'on y peut acheter tout ce qui s'y trouve: talent, éducation, aristocratie. Parlez-lui d'un salon du monde réputé pour sa distinction, il vous dira: «Combien faut-il payer pour y aller ?» La lógica del dinero es la clave identitaria yankee. Esta manera de entender el mundo se conjuga con una gran versatilidad para asimilar con rapidez las normas civilizadas. El cronista concluye este retrato con esta previsión: «Cependant le yankee se perfectionne visiblement au contact de la vieille civilisation européenne, et, comme il va vite dans tout ce qu'il fait, avant peu il sera plus policé que nous» ${ }^{8}$

A continuación, el autor francés se ocupa de la fisiología del sudamericano y la figura se vuelve caricaturesca y circense. «Rastaquouère à Paris» comienza con el dato racial de mestizaje para seguir con la moral signada por la ostentación de nuevo rico. En pocas líneas queda catalogado como exótico y rastaquouère:

un américain, mais du midi. C'est le Marseillais du Nouveau Monde. Il est exubérant, voyant, clinquant, bruyant. Bien que la mot rastaquouère soit appliqué à Paris à tous les exotiques, le vrai, le seul rastaquouère est Brésilien, Chilien, Bolivien, Argentin et Vénézuélien.

15 En la descripción de su apariencia física y estética -que parece dañar la vista y el olfato de los parisinos- lo deja etiquetado dentro del mal gusto, el desborde y la falta de educación: «Sa figure a le ton du vieux bois, ses cheveux noirs sont luisants et parfumés, sa toilette est criarde et trop riche (...) sa présence vous est signalée par un éclat insupportable et des parfums idem. Diamant et musc» ${ }^{10}$.

El retrato del sudamericano se presenta animalizado, con una gesticulación exagerada incapaz de comunicar y con una lengua - el español- que brota con sonidos similares a los ruidos de las cacerolas al caer o chocar entre sí: «De plus près, il vous absorbe dans un flot de grimaces et un flux de paroles vertigineuses, prononcées avec une sonorité de casserole». 
17 Finalmente, se detalla su moral ansiosa por el disfrute y una intensa necesidad de ser aceptado que lo puede llevar a la pérdida de todo, al desastre: «Le plaisir est son but, sa vie, son rêve. Il y laisse toute sa vigueur et toutes ses plumes. C'est un bon garçon que l'on exploite plus qu'il n'exploite les autres [...] finit presque toujours dans la peau d'un décavé» ${ }^{11}$.

Tal como era costumbre en la prensa de Buenos Aires, un diario porteño transcribió parte de esta publicación de Le Figaro con «la fisonomía del americano parisiensado que va a dejar a la capital del placer, sus lustrosos billetes de mil francos, en cambio de algunas sensaciones pasajeras y superficiales» ${ }^{12}$ y es Martin García Mérou quien se ocupa de responderle «al autor satírico» a partir de otro perfil. En realidad, se trata de un descargo para los propios compatriotas con la idea de corregir al escritor francés desde una interpretación distinta de este tipo social bastardeado por ser exuberante, llamativo y ruidoso, tal como lo describe el francés.

García Mérou pone de relieve las exageraciones del francés, que: «todo lo convierte en motivo de piruetas y de intermedios clownescos» siendo el mismo Millaud el verdadero $\mathrm{y}$ «idelicioso personaje!» de sus humoradas. De esta forma, sugiere entender ese perfil del sudamericano como humorada, o farsa desopilante. Sin embargo, agrega que «en París, el extranjero es propiedad de una multitud microbiológica de tiranos que lo acechan, lo persiguen y lo estrujan como un limón»» ${ }^{13}$. Para el escritor argentino, la inmoralidad es la de París y su aristocracia de librea, sus monstruos insaciables. Y el rastaquouère es capaz de reconocer que «París le pertenece por un mes, por una semana, o por un día [...] y a París le entrega entonces, "su sangre juvenil, su amor y su patrimonio" $" 1$. Lo inédito de la crónica de Garcia Mérou es el hecho de que un intelectual sudamericano se decida a responder, corregir y desautorizar a la prensa francesa.

\section{«Ayons donc du courage, Parisiens mes frères»-Le Figaro} sudamericanos. La historia cuenta sobre una joven sudamericana que viaja a París junto con su padre, un hacendado rico y presidente de Tierras Calientes (un nombre de ficción) que buscará casar a su hija con alguien de la aristocracia europea.

Gaston Jollivet, un periodista, escritor y dramaturgo atento al humor social decidió escribir -a propósito de las repercusiones de la comedia- "Rastaquouères d'hier et d'aujourd'hui» ${ }^{16}$ que Le Figaro publicó en primera plana. La nota desarrolla una extensa argumentación a favor de la tolerancia frente a los sudamericanos etiquetados peyorativamente bajo el nombre de exóticos rastaquouères. Los razonamientos de esta nota editorial con tres columnas no responden a valores como el bien común ni la consideración de una estimable y compartida latinidad o simplemente de la fraternidad entre los hombres.

El texto despliega dos ejes para convencer al parisino de cambiar la actitud frente a los acaudalados sudamericanos en su visita a Europa. Por un lado, el texto sostiene desde la necesidad de reconocer a la propia ciudad de París como un gran mercado de objetos materiales e inmateriales y una mercancía en sí misma. La capital francesa es parte 
sustancial del juego de la oferta y la demanda y los sudamericanos nuevos ricos pueden y quieren consumir. Sin embargo, la urbe necesita de ellos como turistas y clientes dentro de una red moderna de consumos. Dice:

Dépenser et toujours dépenser. Ils s'en acquittent avec une telle régularité qu'on dirait d'un voeu. Interrogez les modistes et les couturières. Beaucoup vous avoueront qu'elles seraient obligées de fermer boutique n'était leur clientèle sudaméricaine. Questionnez les hôteliers. Par qui se trouvent occupés actuellement les premiers étages de leurs établissements? Par des Sud- Américains. Chacune de ces familles laisse en moyenne quinze ou vingt mille francs par mois dans notre capitale. Vous me direz qu'ils maintiennent ainsi la cherté de prix des objets de luxe, mais le luxe c'est la raison de vivre de Paris ${ }^{17}$.

Y luego, la crónica aconseja a los franceses el ejercicio de tolerancia. Desde una historia geopolítica y cultural indiscutible, expone una razón fundamental que convalidar las asimetrías entre Francia y las naciones de América Latina como México, Chile o Argentina a las que se debe contemplar como «hermanas menores»:

Tous ces peuples considèrent la France comme une soeur aînée. Tous se proclament les héritiers de notre civilisation. Heureux héritiers qui ont pu ne pas l'être sous bénéfice d'inventaire, n'ayant point de déshérités de la vie autour d'eux! Au Mexique, malgré les souvenirs d'il y a vingt-cinq ans, les coeurs vibrent à tous les échos de France. Pendant la guerre franco-prussienne, des poètes argentins ont écrit de beaux vers en l'honneur de la grande Nation blessée, en même temps qu'aux frais des particuliers s'organisait une légion de volontaires qui a débarqué à temps en France pour prendre une part active à la défense du sol. Croirait-on que, dans plusieurs petits villages semés au sein de la pampa, des gauchos ont porté le deuil de Victor Hugo et, Dieu me pardonne! celui de Gambetta? ${ }^{18}$

La alusión a los poetas argentinos que habían escrito poemas en honor a Francia durante la guerra con Prusia, así como la formación de una legión de voluntarios en defensa del suelo francés responde a una referencia y un dato de la realidad histórica que demuestra la francofilia en países como Argentina. La imagen que le sigue, la de los gauchos es insólita: «dans plusieurs petits villages semés au sein de la pampa, des gauchos ont porté le deuil de Victor Hugo et, Dieu me pardonne! celui de Gambetta». Vale aclarar que el gaucho pertenece al tipo social desclasado ubicado en la frontera misma entre civilización y barbarie, un tipo exótico a la mirada eurocéntrica y que figura siempre en los relatos de viajeros extranjeros que recorrieron la pampa argentina. El periodista de Le Figaro dice que los gauchos llevaron luto por Víctor Hugo y esa imagen es desopilante y exagerada, aunque efectiva para el clímax con el que lograr un buen final de nota y convencer a los lectores de predisponerse mejor para soportar a los viajeros sudamericanos en Francia.

\section{Al insulto colectivo a las hispanoamericanas... un don Quijote de la pluma}

Fue también Le Figaro el diario que le aseguró un espacio a la crítica de las uniones matrimoniales celebradas entre la aristocracia europea empobrecida y «las Pepas auténticas de América del Sur». El escritor y ensayista ecuatoriano Juan Montalvo ${ }^{19}$ quien vivió por largas temporadas en París escribió un descargo con el título de Matrimonios «deslayados» con la intención de presentar una contestación de desagravio. 
26 En un momento introductorio, Montalvo comenta las condiciones que motivaron la escritura. Y cuenta que Alberto Del Solar, el escritor y miembro de la legación chilena en París, se acercó a visitarlo una tarde en representación de muchos otros de la colonia hispanoamericana para solicitarle que fuera él quien escribiera una contestación contundente a «una invectiva terrible contra los hispanoamericanos que traían a sus hijas a buscar marido en París, y principalmente contra las hispanoamericanas que venían a comprar marido» ${ }^{20}$. Se le pide que escriba la «contestación correspondiente» para ser publicada en el propio Le Figaro y en francés, aunque costase una suma considerable.

Ciertamente, el ensayo de Montalvo escrito a pedido de la colonia hispanoamericana en París en 1887 es un texto de confrontación cultural en el que hay una fuerte carga irónica y preguntas retóricas que buscan marcar la devaluación del pensamiento francés, la decadencia de los valores humanísticos:

Al leer uno ciertos artículos de periódico que han salido en estos días se pregunta asombrado: ¿Es ésta la patria de Beltrán Duguesclin? ¿Ésta la patria de Bayardo? Las injurias diarias a los hispanoamericanos pasen: los hombres aguantan todo, ni son canallas, o si el agravio no vale la pena de enojarse; pero si las flechas van enderezadas a las mujeres, bien nos mereceremos lo que los franceses dicen de nosotros, si otorgamos con un silencio cobarde y criminal $^{21}$.

El artículo da respuesta responsabilizando a los partícipes: «Entre las que compran marido y los que se venden, decid, caballeros franceses, hidalgos, hijosdalgo, ricoshomes y señores, ¿cuál es la parte más reprensible?» $»^{22}$. Sin embargo, esta invectiva de «don Quijote de pluma»-como se autodenomina- contra la difamación de la prensa periódica francesa pero jamás se publicó en El Figaro por resultar «ya muy caro» sino que apareció junto con otras notas en el segundo volumen de El Espectador, publicado en París y enteramente en español. El hecho de no publicar en uno de los periódicos de mayor tirada de la prensa francesa ni en francés, tal como lo habían solicitado los representantes de las naciones sudamericanas que designaron a Monsalvo como vocero es un dato muy elocuente de estas asimetrías funcionando como muros. El fuerte descargo solo circuló dentro de los márgenes propiamente hispanoamericanos, de lectores de español, es decir, entre los difamados. El descargo se vuelve -en parte- un simulacro de amonestación porque no alcanza nunca a los responsables de aquellas publicaciones maliciosas. Por ello, nuevamente no se trata de una confrontación sino una ilusión de justicia.

\section{Lucio Mansilla -la periferia cultural y «el gato por liebre»}

Como buen viajero observador de fenómenos de su tiempo e incansable causeur y escritor, Lucio Mansilla registra buena parte de las transformaciones de la modernidad, entre ellas, la democratización de la cultura letrada durante el último tercio del siglo XIX. Aunque sus intervenciones no abandonan jamás la confianza en la distinción de la clase oligárquica a la que pertenece y en sí mismo como " genio de los buenos viajes»" Mansilla analiza la condición sudamericana en la escena mundial a partir de las publicaciones de libros que se ocupan de esta región.

En la causerie titulada «Autores, astrónomos y libros para la exportación» de 1889, Mansilla analiza el fenómeno editorial en el contexto de acceso a la cultura de la letra: 
"iCómo han cambiado los tiempos, con los progresos de la cultura moderna, y cuando ya no va quedando perro ni gato que no sepa leer y escribir!» ${ }^{24}$. No solo es evidente el grado de alfabetización alcanzado, sino la dinámica que asume el mercado del libro. Ese mercado a la vez que agiliza la circulación de la letra impresa también mezcla escrituras de distinta calidad y procedencia.

Mansilla reconoce la pérdida de aquellos rasgos que habían funcionado como distintivos de un determinado sector social de poder: escribir e imprimir: «De ese modo, no hay Juan de los Palotes que no haga un libro» ${ }^{25}$.

La modernidad conlleva también este nuevo paradigma que Sainte-Beuve expone en «De la littérature industrielle»:

Cada vez será menos un rasgo distintivo escribir e imprimir. Con nuestras costumbres electorales e industriales, muy pronto todo el mundo, una vez al menos en su vida, habrá tenido su página, su discurso, su brindis, su prospecto, es decir, será autor. De ahí a escribir un ruin folletín ya no hay sino un paso. ¿Y por qué no también yo?, se preguntan todos ${ }^{26}$.

En este contexto, Mansilla se interesa por una publicación de Émile Blavet La vie parisienne (1889) que cuenta con el patrocinio de Émile Zola -responsable del prólogo- y en un momento en el que Zola ya funciona como autoridad, firma y marca literaria registrada. Sin embargo, para Mansilla, esta publicación es una burla que indigna al lector culto y que pone en evidencia la engañosa publicidad. Zola ha promovido una mercancía falsa y adulterada. Dice Mansilla dirigiéndose en primera persona a Zola y mezclando el español con el francés: «En La Vie Parisienne hay error y mistificación en todo lo que se refiere a la República Argentina». El escritor asume una charla franca con Zola: «que vous, mon cher Zola, qui n'êtes pas fort en Geógraphie, malgré votre immense talent, habéis sido mal renseigné ${ }^{27}$. Y su desilusión es mayor en virtud de la influencia de las ciencias, de las artes, de las letras francesas en toda la América Latina-. El aval de Zola a este libro falaz, plagado de errores sobre la Argentina «conspira contra el prestigio del pensamiento francés». Y lo que sigue es una rectificación y Mansilla corrige: «nuestro actual presidente no se llama Ulman, sino Celman como todos nosotros sabemos» ${ }^{28}$.

La queja de este excursionista del planeta, tal como se lo ha definido por su manía viajera y su pasión cosmopolita -toca el lugar común sobre este eterno desconocimiento de la identidad cultural americana y los prejuicios negativos que pesan siempre contra Sudamérica:

[...]si uno de nosotros dice por el presidente Carnot, Carbot...equivocándose sólo en una letra, de seguro que pasa por un bárbaro, por un indio, por un créole. Pero un francés cualquiera, patrocinado o no por Zola, puede confundir las especies, y llamarlo Ulman a Celman. ¡Conocen tanto la América allá en Europa!

Mi querido Zola, no estamos en África, aquí estamos en América, en donde tiene usted millares de admiradores, a pesar de lo verde de su literatura. Y entonces, ¿por qué razón contribuye usted a que un plato, que nosotros creemos que debe ser liebre, porque es usted el que lo condimenta, resulte gato? ${ }^{29}$

Mansilla reconoce las asimetrías culturales dentro de la lógica de un mercado editorial globalizado. Escribe en español y dentro de la columna «Entre-Nos, causeries de los jueves»-repitiendo en parte aquel título de Sainte Beuve ${ }^{30}$-para su serie de «conversaciones escritas» publicadas desde 1888 en el Diario Sud-América y escritas exclusivamente para sus compatriotas. 


\section{A modo de conclusión}

El perfil de lo sudamericano que las publicaciones francesas hicieron circular en el último tercio del siglo XIX y a propósito de esa «condición sudamericana» construida en las zonas de contacto y dentro de un orden mundial ya globalizado motivó no solo crispación entre algunos criollos sino la necesidad de responder a la ofensa. Esta reacción por parte de los escritores sudamericanos es novedosa en virtud de su pertenencia a tradiciones culturales de hispanofobia y donde Francia siempre fue el ideal civilizatorio.

Los textos sudamericanos que intentaron establecer una confrontación desde la periferia y en español, fueron leídos por compatriotas y, en algún caso, por la colonia hispanoamericana en París. Por ello no se trató de un diálogo real sino de fijar un posicionamiento frente a sus propios compatriotas, conscientes de que la prensa francesa jamás se enteraría de tales amonestaciones. Estas réplicas al vacío, en tanto textos, colaboraron, sin embargo, con la construcción de una imagen del letrado sudamericano capaz de establecer una confraternidad frente al agravio. Se trata de buenos ejercicios que favorecieron una instancia de interpretación nacional y regional, alguna expresión nacionalista y posibilitaron una forma de descargo inédita que reposicionó -también gracias a la democratización de la cultura letrada- a los propios escritores sudamericanos frente a sus compatriotas. A escala global no lograron confrontaciones culturales reales sino más bien simulacros de interpelación y polémica en virtud de que las asimetrías culturales se mantuvieron como muros demasiado sólidos.

\section{BIBLIOGRAFÍA}

Sandra CONTRERAS, El excursionista del planeta. Escritos de viaje, Buenos Aires, Fondo de Cultura Económica, 2012.

Gloria CHICOTE y Miguel DALMARONI, El Vendaval de lo Nuevo. Literatura y cultura en la Argentina moderna entre España y América Latina, Rosario, Beatriz Viterbo, 2008.

Silvana GARDIE, «La figura del rastaquouère: Viaje y literaturas periféricas (1880-1915)», Revue HispanismeS, $\mathrm{n}^{\circ} 12$ (second semestre 2018), Le «nomadisme» dans les mondes hispaniques, Fernando Copello, Dominique Neyrod et Lucie Valverde (eds.), p. 65-74 [fecha de consulta: 20 de marzo de 2021] <URL: http://www.hispanistes.fr/index.php/31-hispanismes/1457-hispanismes-n-12>.

Christian goubault, «Maupassant et la Presse parisienne», Revue d'Études Normandes, no 2, vol. 43 (1994), p. 93-104.

Le Figaro del 11-10-1886, en la 4ta columna de la primera plana.

Le Figaro, 12-11-1888, 1era plana.

Lucio V. MANSILLA, «Autores, astrónomos y libros para la exportación», Entre-nos: Causeries del jueves, t. 3, Primera edición, Buenos Aires, Casa Editora de Juan A. Alsina,1889. 
Martín GARCíA MÉROU, Perfiles y miniaturas, Buenos Aires, Coni, 1889, p. 17-24.

Juan MonTALVo, «Los matrimonios deslayados», El Espectador, t. 2 (15 de junio de 1887), París, Librería Franco-Hispanoamericana, 1887, p. 1-13.

Enrique Popolizio, Vida de Lucio V. Mansilla, Buenos Aires, Editorial Pomaire, 1985.

Marie-Louise PRATT, Ojos imperiales. Literatura de Viajes y transculturación, Buenos Aires, Fondo de Cultura Económica, 2011.

Charles-Augustin SAINTE-BEUVE, «De la littérature industrielle», Revue des deux mondes, t. 19, quatrième série, vol. 4 (1839), Au bureau de la Revue des Deux Mondes, París, p. 681.

\section{NOTAS}

1. El vendaval de lo nuevo es el título de una publicación en la que se investiga el proceso de formación de la Argentina moderna a partir de su dimensión literaria, la lengua, la posición de los intelectuales, las formas de la prensa periódica, los hábitos de lectura emergentes, es decir, los distintos aspectos vinculados con la democratización de la cultura letrada dentro del periodo que va de fin del siglo XIX hasta 1930. Ver: Gloria CHICOTE y Miguel DALMARONI, El Vendaval de lo Nuevo. Literatura y cultura en la Argentina moderna entre España y América Latina, Rosario, Beatriz Viterbo, 2008.

2. El viaje es necesario para la propia educación de los futuros dirigentes, según señala Lucio Mansilla, en febrero de 1881, en una causerie llamada «Sobre Cubierta» y en la que promueve el viaje trasatlántico, convencido de que: «Todo americano que no haya salido de su terruño, por más ingenio y talento que tenga, por mucha instrucción o ilustración que posea, por más que conozca muchas lenguas, por más elástico y flexible que sea, llámese: Roca, Goyena, Estrada [...] obedecerá fatalmente a las influencias del medio, con detrimento de su propia virtualidad» (2012:313). En Sandra CONTRERAS, El excursionista del planeta. Escritos de viaje, Buenos Aires, Fondo de Cultura Económica, 2012, p. 313.

3. Ver Silvana GARDIE, «La figura del rastaquouère: Viaje y literaturas periféricas (1880-1915)», HispanismeS, $\mathrm{n}^{\circ} 12$ (second semestre 2018), Le «nomadisme» dans les mondes hispaniques, Fernando Copello, Dominique Neyrod et Lucie Valverde (eds.), p. 65-74 [disponible al 29 de marzo de 2021] <URL: http://www.hispanistes.fr/index.php/31-hispanismes/1457-hispanismes-n-12>.

4. Christian goubault, «Maupassant et la Presse parisienne», Revue d'Études Normandes, no 2 , vol 43 (1994), p. 93 [disponible al 29/03/2021] <URL: https://www.persee.fr/doc/ etnor_0014-2158_1994_num_43_2_2141 >.

5. Marie-Louise PRATT define «mirada imperial» como aquella capaz de transformar un viaje o expedición o exploración científica de una nación europea en un viaje de vigilancia territorial, apropiación de recursos y/o de control administrativo de cualquier región del globo no europea o pensada como periférica. Ver Ojos imperiales. Literatura de Viajes y transculturación, Buenos Aires, Fondo de Cultura Económica, 2011.

6. Se publican semanalmente dentro de una columna con este mismo nombre desde 1885 en Le Figaro. En 1887 las Physiologies parisiennes se reúnen bajo la forma de libro ilustrado por Caran d'Ache.

7. El retrato de los americanos aparece en Le Figaro del 11 de octubre de 1886, en la 4ta columna de la primera plana que continúa en primera columna de la 2 da página. Todas las citas corresponden a esta referencia.

8. Id.

9. Id. 
10. Id.

11. Id.

12. Martín GarCía mérou, Perfiles y miniaturas, Buenos Aires, Coni, 1889, p. 17-24.

13. Ibid., p. 21

14. Ibid., p. 24.

15. Pepa, comedia en 3 actos (con Louis Ganderax), fue estrenada en la Comédie Française el 31 de octubre de 1888. Por su popularidad, Del Solar la utiliza como referencia importante en su novela. El Periódico Gil Blas le dedica el 2-11-1888 una crítica breve y un extracto del primer acto a modo de publicidad de la obra en cartel [disponible al 29/03/2021] en <URL: https://gallica.bnf.fr/ark:/ 12148/bpt6k7522730b.item>.

16. Le Figaro, 12-11-1888, 1era plana. Todas las citas que siguen corresponden a esta misma publicación [disponible al 29/03/2021] en <URL: https://gallica.bnf.fr/ark:/12148/ bpt6k280576j.item >.

17. Id.

18. Id.

19. Juan montalvo, «Los matrimonios deslayados» en El Espectador, t. 2 (15 de junio de 1887), Paris, Librería Franco-Hispanoamericana, 1887, p. 1-13, [disponible al 29/03/2021] <URL: https:// books.google.com.ar/books/about/El_espectador.html?id=oFoUAAAAYAAJ\&redir_esc= >.

20. Ibid., p. 4.

21. Ibid., p. 6.

22. Ibid., p. 11.

23. Así se autodefine Lucio Mansilla en la nota «Sobre Cubierta» bajo el seudónimo Juan de Dios en 1881.

24. Lucio V. MANSILLA, «Autores, astrónomos y libros para la exportación» en Entre-nos: Causeries del jueves, t. 3, primera edición, Buenos Aires, Casa Editora de Juan A. Alsina, 1889 [disponible al 29/03/2021] <URL: https://upload.wikimedia.org/wikipedia/commons/f/fa/ Entre_Nos._Causeries_del_jueves_III_-_Lucio_V._Mansilla.pdf>.

25. Ibid., p. 200.

26. En el original, dice: «Une première restriction est pourtant à poser dans le blâme. Il faut bien se résigner aux habitudes nouvelles, à l'invasion de la démocratie littéraire comme à l'avènement de toutes les autres démocraties. Peu importe que cela semble plus criant en littérature. Ce sera de moins en moins un trait distinctif que d'écrire et de faire imprimer. Avec nos mœurs électorales, industrielles, tout le monde, une fois au moins dans sa vie, aura eu sa page, son discours, son prospectus, son toast, sera auteur. De là à faire un feuilleton, il n'y a qu'un pas. Pourquoi pas moi aussi ? se dit chacun». En Revue des deux mondes, t. 9, vol. 4 (janvier 1839), Au bureau de la Revue des Deux Mondes, París, p. 681 [disponible al 29/03/2021] <URL: https:// play.google.com/books/reader?id=7XJJAQAAMAAJ\&hl=es_419\&pg=GBS.PA3>.

27. Ibid., p. 213.

28. Id.

29. Id.

30. Dice Mansilla sobre el título: «¡Cuántos no han pensado que eso y charla insustancial era lo mismo! Fue una mala inspiración. Otro error fue no pensar que, sin querer, plagiaba con mi título a Sainte-Beuve. Le agregué luego el subtítulo "Entre nos" [en realidad título, ya que como subtítulo queda el primitivo]», Enrique Popolizio, Vida de Lucio V. Mansilla, Buenos Aires, Editorial Pomaire, 1985, p. 243. 


\title{
RESÚMENES
}

La condition sud-américaine résultant d'un fait racial et d'une origine géopolitique périphérique apparaît dans la presse française du dernier quart du XIX siècle associée à l'exotisme et à la barbarie.

La modernisation des communications et le processus d'expansion de la culture littéraire ont permis une plus grande diffusion des journaux français en Amérique du Sud, ainsi qu'un plus grand nombre de lecteurs périphériques qui ont reçu - par la presse sud-américaine - l'actualité et les chroniques françaises transcrites sous forme d'extraits.Cet article explore certains textes publiés entre 1886 et 1889 par des écrivains sud-américains, notamment contestés par une série de publications dans Le Figaro qu'ils trouvent insultantes. Dans cette intention, ils ont écrit leurs réponses comme s'il s'agissait d'une polémique entre pairs, capable de raccourcir les distances entre le centre et les périphéries et de démolir le mur élevé par les asymétries culturelles.

The South American condition as the result of a racial fact and a peripheral geopolitical appears in the French press of the last quarter of the 19th century associated with exoticism and barbarism. The Modernization of communications and the process of expanding the literate culture provided a greater circulation of French newspapers to South America, as well as a greater number of peripheral readers who received -through the South American press- the French news and chronicles commented or transcribed in the form of extracts. This work investigates some texts that appeared between 1886 and 1889 by South American writers, especially bothered by a series of texts by Le Figaro and other publications that were insulting to them. With this intention, they wrote their answers, reparations or replies as if it were a controversy between peers, as if the distances between the center and the peripheries could be shortened and the wall raised by cultural asymmetries could be demolished.

\section{ÍNDICE}

Keywords: 19th century, South American state, modernizations, periodical press, cultural asymmetries

Mots-clés: 19e siècle, état sud-américain, modernisations, presse périodique, asymétries culturelles

\author{
AUTOR \\ SILVANA GARDIE \\ Universidad Nacional del Sur-Argentina
}

